\title{
Site-Dependence Scalp Cooling System to Prevent Hair Loss during Chemotherapy
}

\author{
Sheikholeslami $\mathbf{M}^{1 *}$, Ghaffari $\mathbf{M}^{2}$, Khorasani $\mathrm{AF}^{1}$ and Zoghi $\mathrm{M}^{3}$
}

${ }^{1}$ Department of Mechanical Engineering, Yazd University, Yazd, IRAN

${ }^{2}$ Department of Bioengineering, University of Illinois at Chicago, Chicago, IL

${ }^{3}$ Department of Mechanical Engineering, Farmingdale State College, SUNY, New York, US

\begin{abstract}
Hair loss (Alopecia) is regarded as the most distressing side effects of chemotherapy in cancer patients. A reduction in cutaneous cell metabolism as a response to the hypothermia could simply make hair follicles less susceptible to drug damage with subdural cooling. In this study, a detailed three-dimensional finite element of human head model is used to investigate the changes in cutaneous blood flow due to heat transfer during the cooling process. Our finite element model consists of scalp, skull (trabecular and cortical bones), all meningeal layers, flax, tentorium, and the brain. Cooling effect was investigated in three different regions of frontal, superior and occipital of the head. The results showed that frontal region is the most sensitive region during cooling, because of the highest contact area between the scalp and the coolant. In order to keep the normal brain condition, the coolant temperature must not be lower than $2^{\circ} \mathrm{C}$. It's also recommended to keep the coolant temperature in range of $-5^{\circ} \mathrm{C}$ to $7^{\circ} \mathrm{C}$. With the constant coolant temperature, the results showed different steady state temperatures in different anatomical regions. It is therefore expected to design a new scalp cooling cap to provide site-dependence temperature with respect to different head regions for optimum heat transfer.
\end{abstract}

Keywords: Heat transfer; Three-dimensional FE head model; Alopecia; Scalp cooling

\section{Introduction}

Chemotherapy as a cancer treatment often leads to partial or complete hair loss (alopecia). It is one of the most distressing and traumatic side effects of cancer therapy [1,2]. It causes psychological stress [3]; negative impact on body image [4], self-esteem [2] and social relations [5], which might lead to treatment rejection by some patients [6,7]. Chemotherapy-induced alopecia is caused by the effects of the chemotherapeutic drug on the hair follicle that continuously receive blood supply from the superficial scalp arteries [8]. Cooling the scalp during chemotherapy treatment can reduce or even prevent this hair loss [9] and is generally very well tolerated by the patient [10]. Two possible mechanisms explain how scalp cooling might contribute to hair preservation [11]. First, blood flow reduces due to the cutaneous tissue condensation during cooling which leads to a reduced drug supply to the hair follicle. Second, a reduction in cutaneous cell metabolism as a response to the hypothermia could simply make hair follicle less exposed to drug.

In this study, a cooling cap is used to cool the scalp in which the coolant fluid is adjusted to the desired temperature in flow state by a cooled reservoir. To lower the scalp temperature, the fluid in this system is circulated with specific temperature and flow rate in the cap; therefore, heat is scavenged from the patient's scalp. The brain heat transfers through free convection and evapotranspiration, while heat generation occurs from two perfusion and metabolism sources. Considering the brain sensitivity, empirical assessing and testing the effect of various conditions on this tissue heat transfer is not an appropriate option. Numerical simulation is an efficient solution to overcome this limitation. Through measuring the evapotranspiration and the transported heat inside the head tissues and their synergic impact in creating free convection in the vicinity of scalp, under controlled environmental conditions; then, applying the desired conditions in the model, it is possible to examine different effective conditions in this heat transfer.
Clark et al. [12] in a pure empirical measurement determined free convection around the head. The study conducted by $\mathrm{Xu}$ et al. [13] involved mathematical modeling of brain cooling with constant temperature boundary conditions. For the first time, Murakami et al. [14] numerically studied heat regulation induced by respiration in their model. They proposed a method for simulation composed of airflow, thermal radiation, and moisture transport to predict heat release from a human body. Vanleeuwen et al. [15] applied a temperature as low as $10^{\circ} \mathrm{C}$ on an infant head. Their results showed that only surface areas of the brain are cooled down to $34^{\circ} \mathrm{C}$. They observed no significant temperature change in the deeper areas. Denis et al. [16] proposed some temperature distribution model of an adult human under cold therapy by putting ice on the scalp. Applying the convection and radiation heat transfer on body surface in $3 \mathrm{D}$ state, Sorenson and Voight [17] modeled the body heat with constant skin temperature condition using computational fluid dynamics. Sukstanskii et al. [18] used the analytical method to investigate the effect of various factors on the brain temperature and reported input blood flow and temperature to tissue as the only effective parameters in brain temperature. Johnson et al. [19] studied the relationship between scalp temperature and blood flow during the cooling process using a 1D modeling. In another work, Johnson et al. [20] empirically measured scalp temperature and blood flow in a laboratory through the scalp cooling using cooling cap.

Considering the $3 \mathrm{D}$ structure and complex geometry of the human brain, it is essential to use $3 \mathrm{D}$ modeling for higher accuracy and

*Corresponding author: Sheikholeslami M, Department of Mechanical Engineering, Yazd University, Yazd, IRAN, Tel: +98 913856 5019; E-mail: mohamad.sheikholeslam@gmail.com

Received: May 01, 2015; Accepted: June 30, 2015; Published: July 16, 2015

Citation: Sheikholeslami M, Ghaffari M, Khorasani AF, Zoghi M (2015) SiteDependence Scalp Cooling System to Prevent Hair Loss during Chemotherapy. J Bioengineer \& Biomedical Sci 5: 158. doi:10.4172/2155- 9538.1000158

Copyright: @ 2015 Sheikholeslami M, et al. This is an open-access article distributed under the terms of the Creative Commons Attribution License, which permits unrestricted use, distribution, and reproduction in any medium, provided the original author and source are credited. 
efficiency in simulating scalp heat transfer. The present study provides a 3D human head model and a cooling cap to examine the heat transfer between the coolant and the skull, scalp and meningeal layers.

\section{Geometry and Boundary Conditions}

The basic geometry of our FE model is based on Horgan and Gilchrist's [21] model, from the BEL repository managed by the Instituti Ortopedici Rizzoli, Bologna, Italy. The point clouds are extracted from the model to form the boundary layers of skull, subarachnoid space and the brain. Since the outer layer of the skull and meningeal layers are important in this study, the model was further modified utilizing new studies on the geometry and thickness of meningeal layers to add more details [22]. Finally, the model was constructed consisting of skull, arachnoid mater, subarachnoid space, pia mater, tentorium, falx, and the brain as shown in Figure 1. The study conducted the numerical simulation of scalp cooling in two steps. In the first step (Step I), the temperature fields are computed in the head assuming constant heat flux due to perfusion and metabolism without cooling cap. In the second step (Step II), the cooling cap is added to the model and the transient unsteady state solution is computed. The results of the first step are set as the initial conditions for temperature distribution in the second step. In the 3D simulation of heat transfer between human head and surrounding head, the fluid (air) and head are initially modeled inside a rectangular cubic area. Figure $2 c$ illustrates human head model and the applied boundary conditions. The fluid speed in the periphery is considered zero (no slip boundary condition). At the bottom wall (marked with blue color) the inlet pressure with constant temperature of $300 \mathrm{~K}$ is set as boundary conditions. At the top wall (shown in red color) the boundary condition is set to be a pressure outlet. These conditions allow air flows to the model from lower boundary and exit from upper boundary. Due to the low height difference $(1 \mathrm{~m})$, the hydrostatic pressure difference induced by the height difference is neglected at its lower and upper surfaces. GAMBIT software is used as preprocessor for mesh generation and for simulation and postprocessing FLUENT software is employed. Continuum, momentum, and energy equations are solved to solve heat transfer. The momentum and energy equations are discretized through second order upwind scheme; whereas the pressure and velocity correlation are solved using the Simple Algorithm. The joining area of neck and head are assumed insulated; hence, the heat transfer effect of the lower body parts is eliminated in this model.

As stated above the cap was added to the model in Step II. In this analysis the followings were determined: 1 ) the interior temperature distribution, 2) the heat transfer (cooling effect) of the head due to blood circulation, 3) the forced heat exchange between scalp and cooling cap, and 4) the generated heat by the intracellular metabolism. Therefore, the model covers the entire simulation of the heat transfer from the

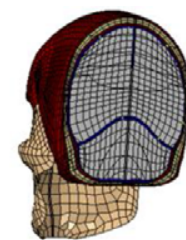

(a)

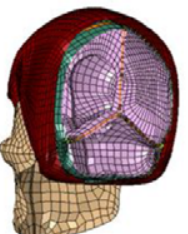

(b)

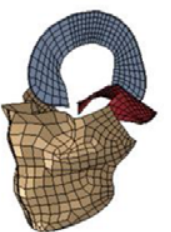

(c)

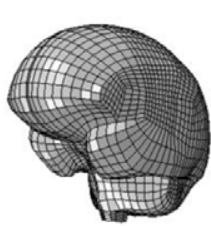

(d)
Figure 1: Finite element mesh of (a) a section cutaway of human head, trabecular bones (yellow color), which are sandwiched by cortical bones (red color) (b) a section cutaway of human head, the brain has been removed to make pia mater visible (purple); (c) flax (blue color), and tentorium (red color); and (d) side view of the brain.

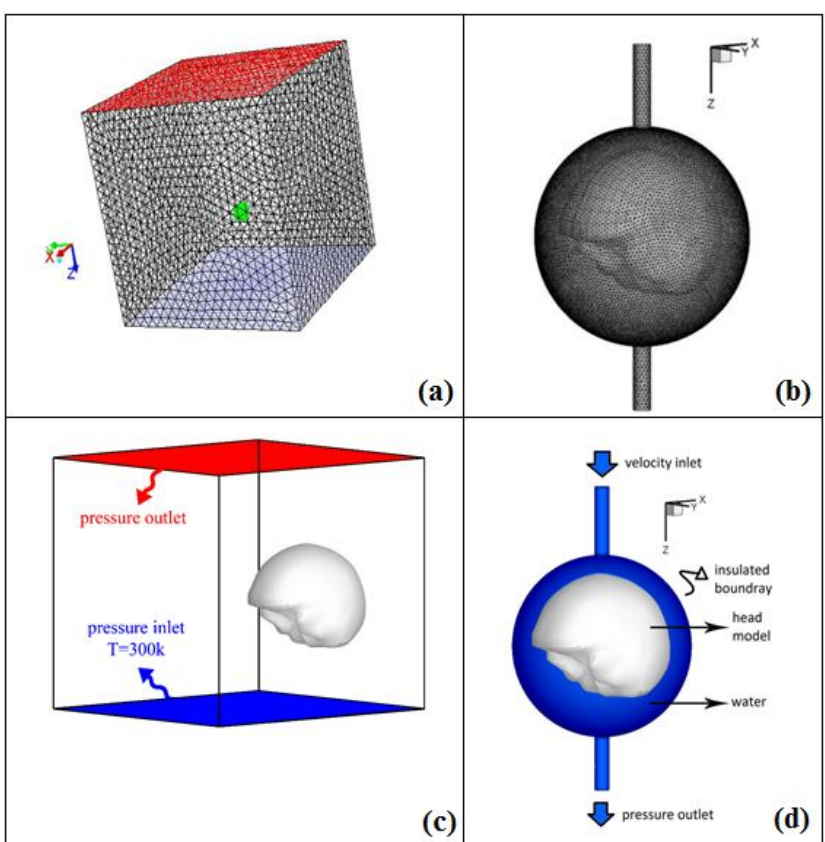

Figure 2: (a) Unstructured mesh generation model for head and fluid domain (b) Meshed model of head and cooling cap (c) The selected model with boundary conditions (d) Head and cooling cap from thefront view with boundary conditions.

head (and its interiors) to the fluid circulating inside the cooling cap. Figure 2d illustrates the model setting inside the cooling cap in Step II.

The cooling cap completely covers the head with no air gap. In this model, the hair effects and the caplayer thickness between the coolant and scalp are neglected. Water is selected as circulating fluid inside the cooling cap that enters from the upper boundary and exits from the lower boundary. The model incorporates convection heat transfer between the cap and the head (through the water medium), and conduction heat transfer through various layers of the head that are in contact with one another. The inlet temperature is set at $0^{\circ} \mathrm{C}$ with a constant flow rate of $0.04 \mathrm{~kg} / \mathrm{s}$. The outlet gauge pressure is set to be $0 \mathrm{~atm}$. All other external boundaries of the cap were assumed insulated with no heat flux. In this analysis, the unsteady method using first order implicit algorithm with time step of 15 seconds is used.

\section{Governing Equation}

To model the heat transfer induced by the blood diffusion in the live tissue, Pennes Bioheat Equation with the effect of surface evaporation $\left(q_{\mathrm{s}}\right)$ was employed. The material properties used for this model are the physical and physiological homogeneous properties from Dennis et al. [16] (Table 1). In the absence of radiation and convection, heat transfer equation is expressed as [23]:

$$
\rho c \frac{\partial T}{\partial t}=\nabla \cdot k(\nabla T)+q_{b}+q_{m}+q_{s}
$$

Where, $\mathrm{K}$ is thermal conductivity, pis density, $\mathrm{C}$ is specific heat, $\mathrm{T}$ is the local tissue temperature, $\mathrm{q}_{\mathrm{s}}$ is heat transfer due to surface evaporation, $q_{b}$ is the heat generation source in form of rate of heat transfer per unit volume due to perfusion, and $\mathrm{q}_{\mathrm{m}}$ is the heat generation source in form of metabolic heat production in the tissue. 


\begin{tabular}{|c|c|c|c|c|}
\hline $\begin{array}{c}\text { Thermo-physical } \\
\text { Properties }\end{array}$ & $\begin{array}{c}\text { Perfusion } \\
\left(\mathbf{k g s} / \mathbf{m}^{\mathbf{3}}\right) \omega_{b}\end{array}$ & $\begin{array}{c}\text { Metabolic rate } \mathbf{( W / \mathbf { m } ^ { 3 } )} \\
q_{m}\end{array}$ & $\begin{array}{c}\text { Density } \mathbf{( k g / \mathbf { m } ^ { 3 } )} \\
\boldsymbol{P}\end{array}$ & $\begin{array}{c}\text { Specific heat } \\
(\mathbf{J} / \mathbf{k g} / \mathbf{K}) \mathbf{C}\end{array}$ \\
\hline Scalp & 0.43 & 33 & 1480 & 2495 \\
\hline Skull & 0.066 & 5 & 1600 & 1500 \\
\hline Brian & 8.6 & 525 & 1000 & 0.34 \\
\hline
\end{tabular}

Table 1: The physical and physiological homogeneous properties of scalp, skull and brain under normal conditions [16].

\begin{tabular}{|c|c|c|c|c|}
\hline $\begin{array}{c}\text { Thermo- } \\
\text { physicalProperties }\end{array}$ & $\begin{array}{c}\text { Dynamic viscosity } \\
\mathbf{( k g / s / m )} \mu\end{array}$ & $\begin{array}{c}\text { Thermal expansion } \\
\mathbf{( 1 / K ) ~} \beta\end{array}$ & $\begin{array}{c}\text { Density } \\
\left(\mathbf{k g} / \mathbf{m}^{\mathbf{3}}\right) \mathbf{p}\end{array}$ & $\begin{array}{c}\text { Thermal capacity } \\
(\mathbf{J} / \mathbf{k g} / \mathbf{K}) \mathbf{C}\end{array}$ \\
\hline Air & 0.0000178 & 0.0033 & 1.225 & 1006.43 \\
\hline
\end{tabular}

Table 2: Physical properties of air at $300 \mathrm{~K}$ temperature.

Note that, $\mathrm{q}_{\mathrm{b}}$ is the energy generation or output in the tissue volume unit which is controlled by blood flow to maintain the tissue central temperature at its biological balance. According to the Pennes [23], the energy exchange between blood vessels and the surrounding tissue mainly occurs at the level of the capillaries. Therefore, the thermal contribution of blood can be modeled by a so-called heat sink. This energy depends on the temperature gradient between the local tissue and the artery. It is also dependent on the blood diffusion in the given tissue. So, the perfusion heat transfer can be expressed as [23]:

$$
q_{b}=\omega_{b} c_{b}\left(T_{a r t}-T\right)
$$

Where,

$\omega_{b}$ is the volumetric perfusion rate, $c_{b}$ is the specific heat of blood $(3825 \mathrm{~J} / \mathrm{kg} / \mathrm{K}), \mathrm{T}_{\text {art }}$ is the temperature of the arterial blood $\left(37^{\circ} \mathrm{C}\right)$, and $\mathrm{T}$ is the local tissue temperature.

One of the main points of interest in this study is the relationship between scalp temperature and perfusion during cooling. The following equation indicates the blood flow variations with respect to temperature [24]:

$$
\frac{\omega_{b}}{\omega_{b, 0}}=Q_{10}{ }^{\left(\frac{T-T_{0}}{10}\right)}
$$

In which, $\omega_{b, 0}$ is the blood flow in the tissue at natural temperature, $\mathrm{Q}_{10}$ is the perfusion coefficient, and $\mathrm{T}_{0}$ is the tissue temperature at initial condition which was calculated from the Step I simulation.

This equation indicates that by decreasing $10^{\circ} \mathrm{C}$ in the tissue temperature, the blood flow correspondingly decreases with blood flow coefficient $\left(Q_{10}\right)$. According to Denis et al., $Q_{10}$ varies in the range of 2 to 3 [16]. Besides, $\mathrm{q}_{\mathrm{m}}$ is the heat generation potential in volume unit induced by the metabolic activities of the cells in the entire tissue, which is considered as homogenous because of the slight temperature variations in the brain. In the present study, the constant value of 2.5 is used for the head standard model [19].

Perspiration helps maintaining stable body temperature. The water placed in the interface provides the heat needed for evaporation through convection and conduction heat transfer from the lower surfaces. Evaporation rate is controlled by many factors such as water temperature at the water-air interface, atmospheric moisture, surface area of the water-air interface, and water temperature [25]. To model the heat transferred from skin surface by perspiration, a thermal sink was added to the skin outermost layer in the heat reflection manner. As previously mentioned, for the sake of simplification, this heat reflection was assumed constant and equal to the discharged mean heat induced by evapotranspiration under human welfare conditions. Murakami et al. [14] obtained the heat transferred from skin surface induced by evapotranspiration as $24.2 \mathrm{~W} / \mathrm{m}^{2}$. To use this amount in the present study, heat waste should be expressed in volume unit. Assuming constant skin thickness of $3.9 \mathrm{~mm}, q_{\mathrm{s}}$ is therefore obtained as -6208 $\mathrm{W} / \mathrm{m}^{3}$.

The more recent models of live tissue heat transfer involve the impact of vascular system in heat transfer phenomenon inside the body. Since the majority of the tissues do not have any vascular system in this model (except a wide net of capillary systems in the brain), only Pennes Bio heat Equation was performed in this study. Free convection exists in the human body due to temperature gradient between the body and surroundings. This includes the convection in the vicinity of the head where it creates an upward air flow due to the air temperature increase in the head area. In Equation 1, energy conservation equation inside the tissue is linked to the continuum and momentum equations and also the energy inside the fluid around the head. To study the free convection flow, Boussinesq approximation is used. In this method the density is considered as a function of temperature in momentum and energy equations. Therefore, the governing equations in free convection are interrelated because of the temperature changes. As shown in Equations 5 and 6, density change contributes as the main cause of generating volumetric force in the momentum equation. So, the governing equations on fluid around the head (air) are expressed as follows:

$$
\begin{aligned}
& \nabla . v=0 \\
& \rho v \cdot \nabla v=-\nabla p+\mu \nabla^{2} v+\rho g \beta\left(T-T_{a}\right) \\
& \rho c_{p} v . \nabla T=k \nabla T
\end{aligned}
$$

Where, $v$ is velocity, $\mathrm{p}$ is pressure, $\rho$ is density, $\beta$ is the thermal expansion coefficient, $\mathrm{g}$ is gravity, $\mathrm{k}$ is thermal expansion coefficient, $\mathrm{T}_{\mathrm{a}}$ is reference temperature in calculating fluid density, $\mu$ is dynamic viscosityand $\mathrm{Cp}$ is the fluid thermal capacity.

Table 2 presents physical properties for air at $300 \mathrm{~K}$ temperature, which is considered as the environment temperature in this study. Equations 4 is the continuity equation for incompressible flow. Equation 5 represents the momentum equation for incompressible flow with volumetric force term added (the last term in Equation 5) to apply the temperature change. Equation 6 presents equilibrium of convection heat transfer and diffusion in head.

\section{Mesh Generation}

To make the model ready for simulation, unstructured mesh structure was utilized to model the fluid domain; head and fluid interface are discretized using finer mesh size. Figure 2 a presents mesh structure of the head and the head periphery for Step I and Figure $2 b$ 
illustrates mesh generation for the head and cooling cap employed for Step II. To demonstrate mesh size in dependence, three different mesh sizes including coarse (138429 elements), medium (250364 elements), and fine (500283 elements) are investigated. Mean temperature distribution was assessed on the scalp, shown in Figure 3. As indicated, the results remain almost constant with increasing the mesh density. Therefore, the incremental grid size was not necessary and the coarse mesh was sufficiently fine for the analysis.

\section{Validation}

The model was validated against Johnson et al. [19]. Their results indicated that during 50 minutes of cooling, the temperature of scalp drops from the maximum amount of $34.4^{\circ} \mathrm{C}$ to minimum level of $18.3^{\circ} \mathrm{C}$. Thus, relative perfusioninside the skin reaches to its minimum level of $25 \%$. These results are obtained given $4 \mathrm{~mm}$ hair layer thickness in the head modeling. For a more accurate heat transfer between the head and cap, they considered hair thickness as $1 \mathrm{~mm}$ in the next step. In this case, the results showed that the minimum skin temperature reaches $10.05^{\circ} \mathrm{C}$ and the perfusion inside the skin decreases down to $13 \%$ as compared to their natural value. In the present study the scalp temperature dropped from $34.3^{\circ} \mathrm{C}$ to $9.68^{\circ} \mathrm{C}$. Consequently, the perfusion decreased down to $12 \%$ of its natural amount. As shown in Table 3, the response of the model of the present study matched relatively well with Johnson et al. $8 \%$ However, this difference can be attributed to the fact that presence of hair was neglected in the present research.

\section{Results and Discussion}

\section{Step I results}

Mid-sagittal plane of the brain is chosen to record the results. Figure 4 shows the temperature distribution obtained by solving the fluid field and head tissues in the control model. Temperature distribution of the head shows the appropriate thermal convection of this organ

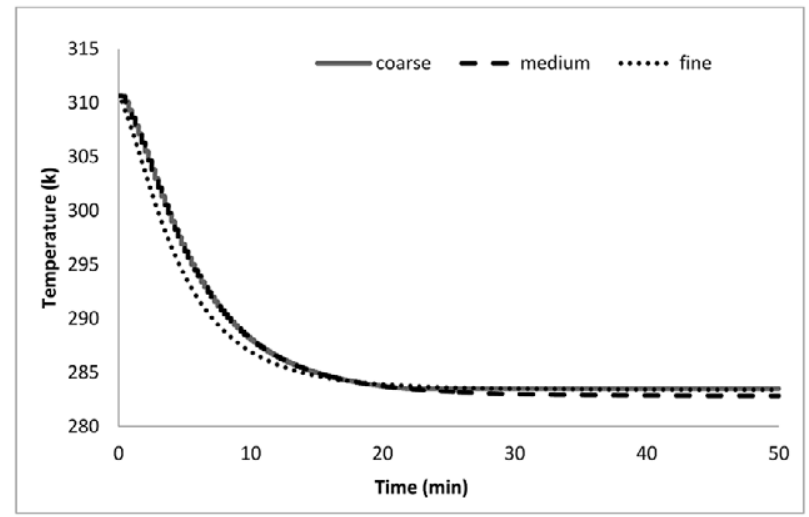

Figure 3: Mean temperature in scalp for different mesh sizes.

\begin{tabular}{|l|c|c|c|}
\hline Model & $\begin{array}{c}\text { Max. scalp } \\
\text { temperature } \mathbf{~}^{\circ} \mathbf{C} \text { ) }\end{array}$ & $\begin{array}{c}\text { Min. scalp } \\
\left.\text { temperature }{ }^{\circ} \mathbf{C}\right)\end{array}$ & $\begin{array}{c}\text { Perfusion } \\
\text { decrease (\%) }\end{array}$ \\
\hline $\begin{array}{l}\text { Johnson et al. with } \\
\mathbf{4} \text { mm hair layer }\end{array}$ & 34.4 & 18.3 & 25 \\
\hline $\begin{array}{l}\text { Johnson et al. with } \\
\text { 1 mm hair layer }\end{array}$ & 34.4 & 10.05 & 13 \\
\hline Present study & 34.3 & 9.68 & 12 \\
\hline
\end{tabular}

Table 3: The model was validated against Johnson et al. As indicated the model matches well with the case with $1 \mathrm{~mm}$ hair layer.
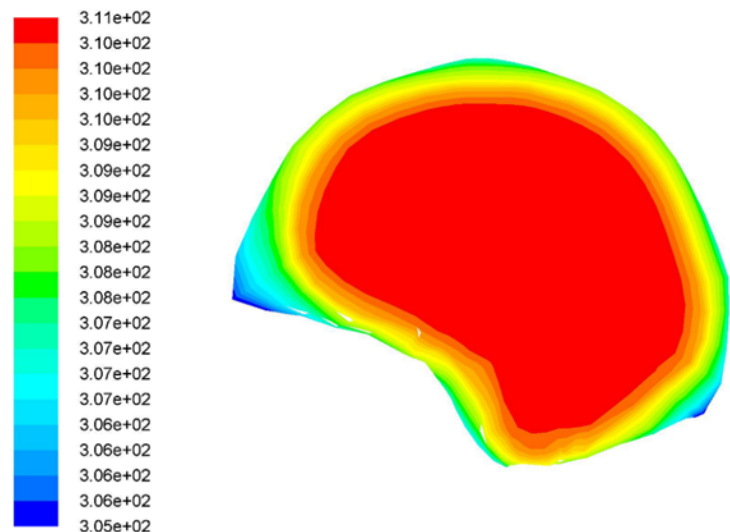

Figure 4: Temperature distribution $(\mathrm{K})$ in mid-sagittal section for a steady flow.

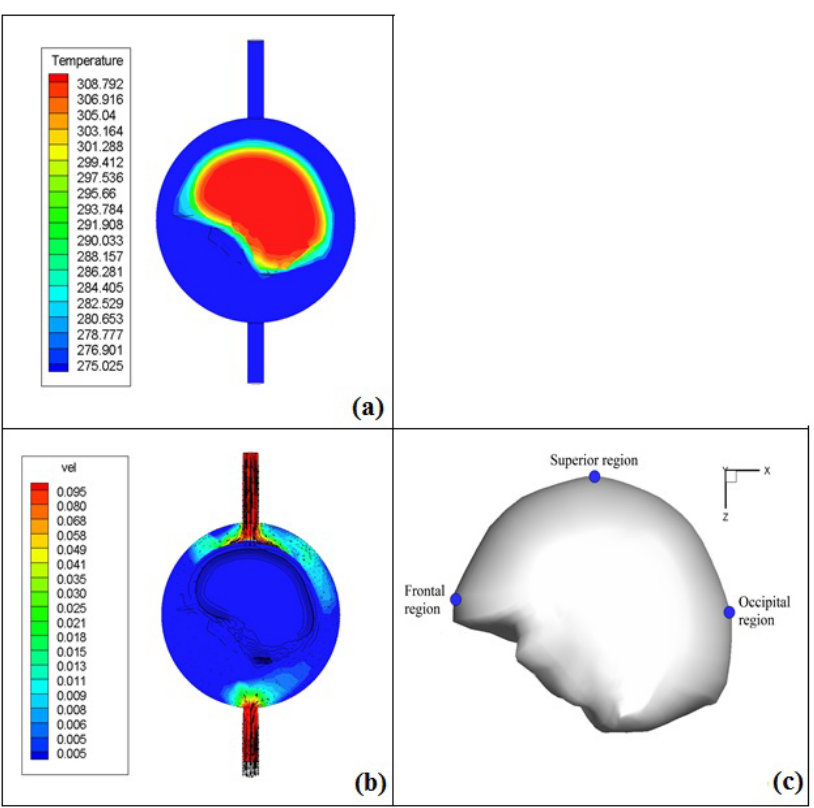

Figure 5: (a) Temperature distribution $(\mathrm{K})$ inside the head at cooling state (b) Fluid flow velocity $(\mathrm{m} / \mathrm{s})$ distribution inside the cap (c) Points assigned in determining temperature distribution in the scalp skin.

with its environment. Considering the governing conditions, through decreasing the environment temperature and reducing the blood flow it is possible to develop the cool layers in the higher depths. Maximum temperature in this model was $37.4^{\circ} \mathrm{C}$ in the brain tissue. Moving towards the scalp, the temperature in other tissues gradually decreases to a minimum level at the surface. Because of the more contact area between the skin surface and air in the anterior and posterior regions, the temperature reached to its minimum value in these regions. In other words, the minimum temperature in these areas is attributed to the lack of heat generation in the surface vicinity and the wider contact area.

\section{Step II results}

In this step, the cap is added to the $3 \mathrm{D}$ human model to analyze human head cooling through its thermal exchange to the circulating fluid inside the cooling cap. Simulation procedure of the scalp cooling continued until the thermal steady state condition was obtained. Figure $5 \mathrm{a}$ 
illustrates the temperature distribution at $\mathrm{t}=3000 \mathrm{~s}$ (50 minutes). Note that the dramatic temperature change occurred in scalp, skull and Meningeal layers and not in the brain which shows the efficacy and validity of temperature parameter in fluid domain. The maximum temperature change happens at $20 \mathrm{~mm}$ from scalp towards the brain. As predicted, the maximum temperature occurred at the center of the brain a region where heat generation is high and the distance for heat transfer between the cold cap and hot biological material is greatest. The velocity of the flow distribution remained constant during the 50 -minute simulation, at $0.045 \mathrm{~m} / \mathrm{s}$ as shown in Figure 5b. This flow enables the cold fluid to stay in motion and continuously removes the flux of heat from the head. The velocity remains highest at inflow where velocity is forced in and the area through which the coolant may flow is the smallest. However, as the fluid spreads out over the cap, it is flowing through a much larger area and therefore slows down dramatically. One of the main objectives of this simulation is to find the appropriate cooling temperature. In this regard, superior region, frontal region and occipital region on head scalp were selected to present temperature distribution inside the scalp tissue (Figure $5 \mathrm{c}$ ). Figure 6 indicates temperature changes inside the scalp for the selected regions. Temperature is separately measured for each region; then, the average is calculated as the main temperature change in the transitional state. The average scalp temperature varying with time is shown in Figure 7. These variations allow detecting the appropriate temperature options in cooling process without making any injury to the scalp.

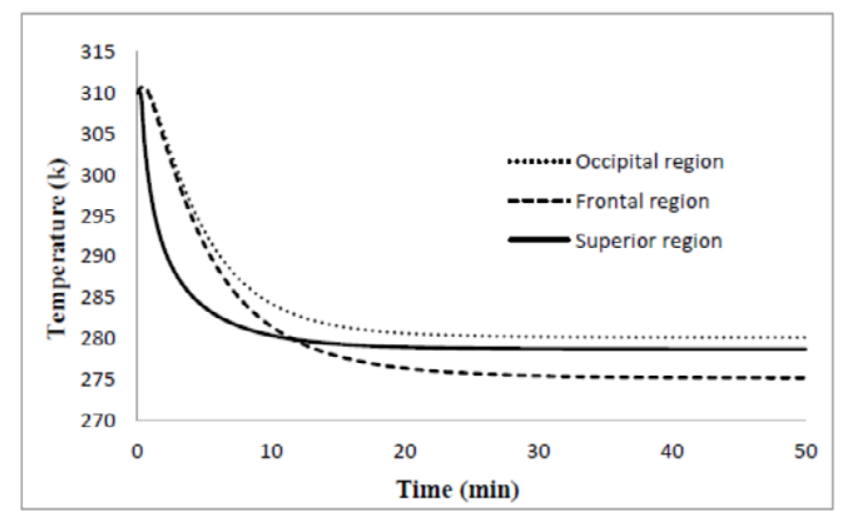

Figure 6: Steady state temperature $(K)$ during the scalp cooling in subarachnoid space in occipital, frontal and superior regions. The maximum temperature drop happened in the frontal region.

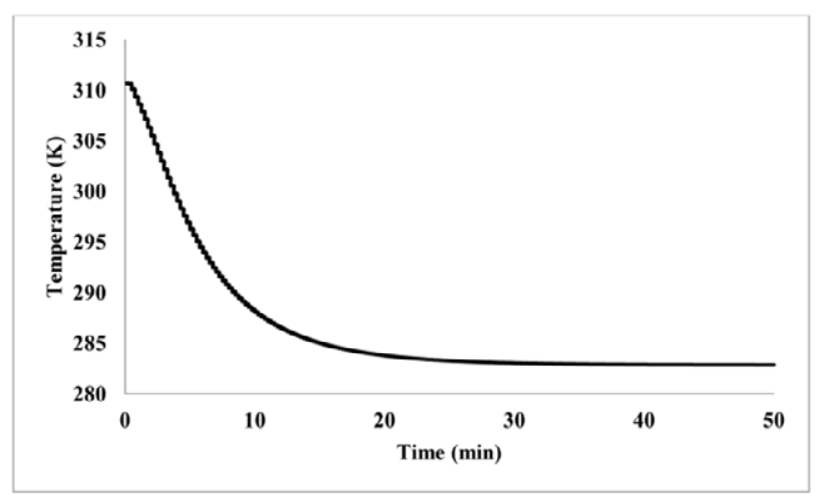

Figure 7: Mean temperature distribution in the scalp skin during the cooling process.

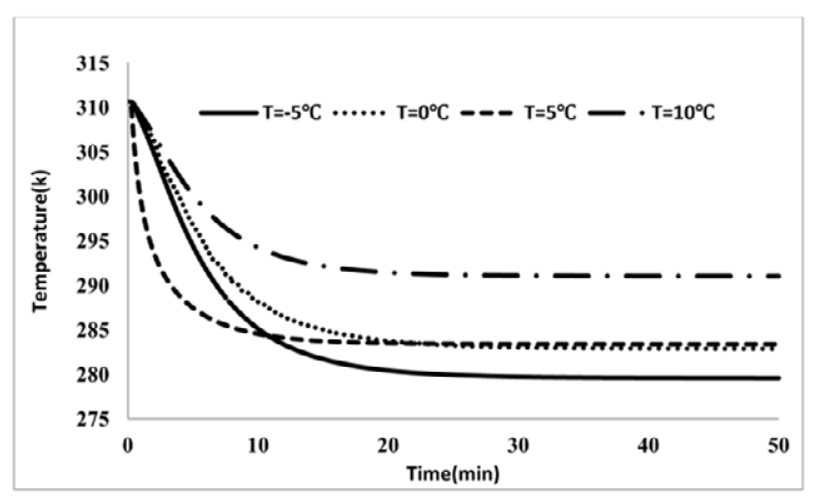

Figure 8: Mean temperature distribution inside the scalp skin for different coolant temperature during the cooling process.

\begin{tabular}{|c|c|c|}
\hline Coolant temperature $\left({ }^{\circ} \mathbf{C}\right)$ & Min. scalp temperature $\left({ }^{\circ} \mathbf{C}\right)$ & Perfusion decrease \\
\hline $\mathbf{- 5}$ & 6.4 & $10 \%$ \\
\hline $\mathbf{5}$ & 10.22 & $13 \%$ \\
\hline $\mathbf{1 0}$ & 17.68 & $21 \%$ \\
\hline
\end{tabular}

Table 4: Effect of changes in coolant temperature on minimum scalp temperature (Tskin) and relative perfusion during cooling.

The results indicated that the scalp temperature during the cooling process reached its minimum value $\left(9.68^{\circ} \mathrm{C}\right)$ from its maximum $\left(34.3^{\circ} \mathrm{C}\right)$. This temperature variation is obtained during 50 minutes followed by steady state condition. Also, the model showed that perfusion drops down to $12 \%$ of normal value when Equation 3 is used to calculate skin blood flow. Figure 8 presents mean temperature distribution over time in human scalp in various water temperatures entering the cooling cap.

Effect of changes in coolant temperature on minimum scalp temperature $\left(\mathrm{T}_{\text {skin }}\right)$ and relative perfusion are shown in Table 4.

The recent studies have shown that there is a relation between head tissues temperature and the protective effect of scalp cooling in preventing hair loss. The main objective of the current study was to investigate the suitable temperature range to minimize the hair loss. Based on this simulation results, cooling is effective only when the scalp temperature drops below $22^{\circ} \mathrm{C}$. In contact temperature, most dropped temperature was seen in sub arachnoid space in the frontal region. Therefore, we considered frontal region as the critical region to compute the lowest possible temperature range. In other words, the frontal region of the brain should keep its normal metabolism during cooling process and the range of acceptable temperature is $35.7^{\circ} \mathrm{C}$ to $34.2^{\circ} \mathrm{C}$. It's recommended to keep the coolant fluid temperature range between -5 to $1^{\circ} \mathrm{C}$ to get the most efficient results. According to the results, the coolant fluid temperature shouldn't be set below $-5^{\circ} \mathrm{C}$. This is done in an attempt to reduce the risk of tissue injury from lack of blood flow. The constant contact with cooling cap may affect head tissues, if the scalp temperature drops below $2^{\circ} \mathrm{C}$. Therefore, this study proposes to keep the temperature at $5^{\circ} \mathrm{C}$ for all points of head tissues to prevent damaging tissues in patients under treatment. In summary, according to the results, if coolant temperature and mass flow rate are set to $-5^{\circ} \mathrm{C}$ and $0.04 \mathrm{~kg} / \mathrm{s}$, respectively, the minimum scalp temperature $\left(6.4^{\circ} \mathrm{C}\right)$ is achieved. This subsequently would have the maximum protective effect against hair loss. 
Citation: Sheikholeslami M, Ghaffari M, Khorasani AF, Zoghi M (2015) Site-Dependence Scalp Cooling System to Prevent Hair Loss during Chemotherapy. J Bioengineer \& Biomedical Sci 5: 158. doi:10.4172/2155- 9538.1000158

\section{Conclusion}

This study was carried out to study site-dependent scalp cooling system in order to enhance reducing hair loss during chemotherapy. The results of this study are matching to those obtained in previous works. At cooling temperature of $-5^{\circ} \mathrm{C}$, the scalp temperature settles on a minimum of $6.4^{\circ} \mathrm{C}$ from the maximum temperature of $34.3^{\circ} \mathrm{C}$ and blood flow pressure reaches $10 \%$ of its natural amount. At the similar period and at $5^{\circ} \mathrm{C}$, the scalp temperature reaches the minimum temperature $10.22^{\circ} \mathrm{C}$ from maximum $34.3^{\circ} \mathrm{C}$ level and blood flow pressure decreases to $13 \%$ of its natural amount. At $10^{\circ} \mathrm{C}$, this temperature drops from $34.3^{\circ} \mathrm{C}$ to $17.86^{\circ} \mathrm{C}$ and blood flow pressure decreases to $21 \%$ of its natural amount.

Hair loss prevention can be achieved by cooling of the scalp without any further deep cooling of the brain. The recent studies have shown that there is a relation between head region temperature and the protective effect of scalp cooling in preventing hair loss.

\section{References}

1. Cash TF (2001) The Psychology of hair loss and its implications for patien care. Dermatologic clinics 19: 161-166.

2. Batchelor D (2000) Hair and cancer chemotherapy: consequences and nursing care a literature study. European journal of cancer care 10: 147-163.

3. Katsimbri P, Bamias A, Pavlidis N (2000) Prevention of chemotherapy-induced alopecia using an effective scalp cooling system. European Journal of Cancer 36: 766-771.

4. Baxley OK, Erdman LK, Henry EB, Roof BJ (1984) Alopecia: effect on cancer patient'sbody image. Cancer Nursing 7: 499-503.

5. Freedman T (1994) Social and cultural dimensions of hair loss in women treated for breast cancer. Cancer Nursing 17: 334-341.

6. Dean JC, Salmon SE, Griffith KS (1979) Prevention of doxorubicin induced hair loss with scalp hypothermia. New England Journal of Medicine 301: 334-341.

7. Klopovich PM, Clancy BJ (1985) Sexuality and the adolescent with cancer Seminar in Oncology Nursing 1: 42-48.

8. Trueb RM (2010) Chemotherapy-induced alopecia. Current opinion in supportive and palliative care 4: 281-284.

9. Protiere C, Evance K, Camerlo J, Ingrado MP, Macquart G, et al. (2002) Efficacy and tolerance of a scalp cooling system for prevention of hair loss and the experience of breast cancer patients treated by adjuvant chemotherapy. Support care cancer 10: 529-537.
10. Ridderheim M, Bjurberg M, Gustavsson A (2003) Scalp hypothermia to prevent chemotherapy induced alopecia is effective and safe: a pilot study of a new digitized scalp cooling system used in 74 patient. Support Care Cancer 11: $371-407$.

11. Grevelman EG, Breed WP (2005) Prevention of chemotherapy-induced hair loss by scalp cooling. Annals of Oncology 16: 352-358.

12. Clark RP, Toy N (1975) Natural convection around the human head. Journal of Physiology 244: 283-293.

13. Xu X, Tikusis P, Giesbrecht G (1999) Mathematical model for human brain cooling during cold water near drowing. Journal of Applied Physiology 86: 265-272.

14. Murakami S, Kato S, Zeng J (2000) Combine simulation of air, radiation and moisture transport for heat release from a human body. Building and Environment 35: 489-500.

15. Vanleeuwen GMJ, Hand JW, Lagendijk JW, Azzopardi DV, Edwards AD (2000) Numerical modelling of temperature distributions within the neonatal head. Pediatric Research Journal 48: 351-356.

16. Dennis BH, Eberhart RC, Dulikravich GS, Randons SW (2003) Finite element simulation of cooling of realistic 3-D human head and neck. Journal of Biomechanical Engineering 125: 832-840.

17. Sorensen DN, Voight LK (2003) Modelling flow and heat transfer around a seated human body by computational fluid dynamics. Building and Environment 38: 753-762.

18. Sukstanskii AL, Yablonskiy DA (2004) An analytical model of temperature regulation in human head. Journal of Thermo Biology 29: 283-587.

19. Janssen FE, Van Leeuwen GM, Van Steenhoven AA (2005) Modelling of temperature and perfusion during scalp cooling. Physics in Medicine and Biology 50: 4065-4073.

20. Janssen FP, Van Leeuwen GM, Van Steenhoven AA, Rajan V, Steenbergen W (2007) The Relationship between local scalp skin temperature and cutaneous perfusion during scalp cooling. Physiological Measurement 28: 829-839.

21. Horgan TJ, Gilchrist MD (2003) The Creation of three-dimensional finite element models for simulating head impact biomechanics. International Journal of Crashworthiness 8: 353-366.

22. Yan W, Pangestu OD (2011) A modified human head model for the study of impact head injury. 14: 1049-1057.

23. Pennes HH (1948) Analysis of tissue and arterial blood temperatures in the resting Human forearm. Journal of Applied Physiology 1: 93-122.

24. Fiala D, Lomas KJ, Stohre M (1999) A computer model of human thermo regulation for a wide range of environmental conditions: The passive system. Journal of Applied Physiology 87: 1957-1972.

25. Incropera F, Dewitt D (2002) Fundamentals of heat and mass transfer John Wiley and sons. 